\title{
The Role of Institutions in Rural-Urban Migration and Urban Unemployment in LDCs: With and Without Changing Level of Indebtedness of the Peasantry
}

\author{
TAMAL DATTA CHAUDHURI ${ }^{*}$
}

This paper attempts to formalise and integrate the roles of "rural push" and "urban pull" factors in rural-urban migration and urban unemployment. Perpetual indebtedness of the peasantry and a monopolistic moneylender, combined with the Harris-Todaro framework, constitute the model. Analysis reveals that such measures might fall short of their goal since the moneylender syphons off part of the benefits that are supposed to accrue to the workers. Possibilities of non-existence of equilibrium and multiple equilibria are pointed out in this model.

\section{INTRODUCTION}

In recent years, a number of papers that have appeared in the fields of economic development and international trade have in common a seminal idea introduced by Harris and Todaro (hereafter referred to as H-T) [6] to explain ruralurban migration and urban unemployment. An institutionally given urban wage rate, and a wage differential between the rural and the urban sector, form the basis of the $\mathrm{H}-\mathrm{T}$ framework. Migration is governed by expected wage equalisation and urban unemployment is solved endogenously from the model. Besides [6], some of the relevant references are Bhagwati and Srinivasan [2], Calvo [3], Corden and Findlay [4], Gersovitz [5], Khan [7] and Stiglitz [9] .

None of the above works considers the role of institutions in the rural sectors of less developed countries in rural-urban migration. High rates of interest on consumption loans and perpetual indebtedness of the peasantry are commonly observed in such economies and such factors play an important role in pushing out people from the rural sector. Indeed, the need for formalising these "push" factors has been pointed out in Lipton [8]. Here we try to model such factors and integrate the model with the analysis present in the above-mentioned literature.

*The author is a Research Scholar in the Department of Political Economy at the Johns Hopkins University, Baltimore, Md. (USA), and this article is part of his dissertation being prepared under the guidance of Professor M. Ali Khan. He is indebted to Professor Khan, Professor Bela Balassa and Professor Bruce Hamilton for helpful discussions. For errors, however, the author alone is responsible. 
In the model under consideration, a particular form of rural institutional set up is formalised which shares some of the characteristics of a semi-feudal rural economy. Such characteristics have been described in detail in Bhaduri [1]. We assume that the rural sector has three classes of agents:

(i) agents who own land and carry on production with the help of labour;

(ii) landless agricultural labourers who sell their labour for survival; and

(iii) a village moneylender who only invests in consumption loans.

The wage rate in the rural sector is determined competitively, but the labourers do not get paid before a crop is harvested. So they have to survive between harvests on their own resources. Also, given the fact that except for their labour power they have no resources of their own, they are forced to take consumption loans. One of the characteristics of such economies is that the peasants are denied the services of the organised credit market. So they are forced to go to the village moneylender for consumption loans. This puts the moneylender in a monopoly position who then exploits the peasantry by charging high rates of interest. Moreover, once the labourers get paid, a large part of their wages is paid out as interest, thus forcing them to take consumption loans again in the next period.

The thrust of the paper essentially hinges on the existence of consumption loans in the rural sector and the monopoly position enjoyed by the village moneylender. We combine these with the essential ingredients of the $\mathrm{H}-\mathrm{T}$ framework. But, instead of the actual rural wage, we equate the "effective" rural wage to the expected urban wage, the rate of distortion between the actual and the effective wage rate being determined endogenously from the model.

The plan of the paper is as follows. Section 2 describes the model, which is analysed in Section 3. Section 4 deals with development policies and some comparative static exercises are performed which bring out the significance of this model. In Section 5, the model is extended to incorporate the implications of movement in the level of outstanding debt of the peasantry. Section 6 concludes the paper.

\section{MODEL}

There are two sectors in the economy, rural and urban, represented by indices $\mathrm{r}$ and $\mathrm{u}$ respectively. Production is carried on in both sectors with the help of labour and capital, where capital is assumed to be non-shiftable or sector-specific. Let the $\mathrm{j}^{\text {th }}$ sector produce a commodity $\mathrm{X}_{\mathrm{j}}$ in accordance with the production function

$$
X_{j}=F_{j}\left(L_{j}, K_{j}\right), \quad j=r, u
$$

which is assumed to be homogeneous of degree one, twice continuously differentiable and concave. The allocation of $\mathrm{L}_{\mathrm{j}}$ is determined by marginal productivity pricing, i.e.

$$
P_{j} \frac{\partial F_{j}}{\partial L_{j}}=P_{j} F_{j}^{L}=w_{j}, j=r, u
$$

The country is too small to influence $\mathrm{P}_{\mathrm{r}}$ and $\mathrm{P}_{\mathrm{u}}$, positive international prices of the two commodities.

Following $\mathrm{H}-\mathrm{T}$, we assume the urban wage rate to be institutionally given at

$$
\begin{aligned}
& \mathrm{w}_{\mathrm{u}}=\overline{\mathrm{w}}_{\mathrm{u}} \\
& \mathrm{L}_{\mathrm{r}}+(1+\lambda) \mathrm{L}_{\mathrm{u}}=\mathscr{L} \ldots
\end{aligned}
$$

gives the distribution of the total labour force, $\mathscr{L}$, over the two sectors, $\lambda$ standing for the ratio of urban unemployment to urban employment.

The question now is: what determines the volume of consumption loan, $c_{r}$, taken by a rural worker? In this section, we assume that there is neither accumulation nor 'decumulation' of debt. Any volume of consumption loan is fully consumed by the worker, leaving neither savings nor outstanding debt. Since the consumption loan is repaid with interest from the wages earned, we have

$$
c_{r}(1+i)=w_{r}
$$$$
\text { . }
$$

where $\mathrm{i}$ stands for the rate of interest charged on the consumption loan. As $\mathrm{w}_{\mathrm{r}}$ is assumed to be determined competitively, the moneylender has no control over $w_{r}$, and hence $c_{r}$ depends on i only, ic representing the extent to which a rural worker is exploited by the moneylender. $c_{r}=w_{r} / 1+i$ can then be labelled as the "effective wage" of a landless agricultural labourer.

We now turn to an analysis of a rural worker's decision to migrate. Since $c_{r}$ stands for the volume of consumption loan he can get during a certain production period, this determines his standard of living in that period. If the expected wage in the urban sector is greater than $c_{r}$, then it is in the interest of the worker to migrate to the urban sector. Hence, migration is governed by

$$
c_{r}(1+\lambda)=w_{u}
$$

where $1 / 1+\lambda$ is the probability of getting a job in the urban centre.

In order to complete the model, we need to determine the rate of interest, "i". Two such methods are considered. The first involves a quit function which captures the possibility of a rural worker taking a loan and then slipping away to the 
urban sector. The second incorporates the idea that the moneylender can control the supply of labour to the rural sector by changing the rate of interest. But whichever method we consider, from equations (2.5) and (2.6) we observe that it is not in the interest of the moneylender to charge an arbitrarily high rate of interest since, given $\mathrm{w}_{\mathrm{r}}, \mathrm{w}_{\mathrm{u}}$ and $\lambda$, the worker might be pushed out. Given that his objective is to maximise total returns from moneylending, it is in his interest to see that the rural labourer does not migrate.

In our first approach, let " $p$ " be the probability that a labourer will stay in the rural sector. Then $(1-p)$ is the proportion of loans defaulted. The probability of staying depends on the rural-urban wage ratio, the extent of urban unemployment and the rate of interest on consumption loans. So,

$$
\mathrm{p}=\mathrm{p}\left(\mathrm{w}_{\mathrm{r}} / \mathrm{w}_{\mathrm{u}}, \lambda, \mathrm{i}\right) \quad \ldots
$$

where we assume that $\mathrm{p}_{1}>0, \mathrm{p}_{2}>0, \mathrm{p}_{3}<0, \mathrm{p}_{\mathrm{i}}$ 's standing for the partial derivatives of the p-function with respect to its arguments. Thus when the urban unemployment rate, $\lambda$, and/or the rural-urban wage ratio increases, the probability to stay increases. But when the rate of interest increases, then, given the values of the other variables, that probability decreases.

When a rural worker quits, the moneylender loses the interest on the loan given and he suffers a capital loss equal to the volume of the loan defaulted. ${ }^{1}$ His problem is then to maximise the net returns per unit of loan advanced, i.e.

$$
\underset{i}{\operatorname{Max}}\left\{\operatorname{ip}\left(w_{r} / w_{u}, \lambda, i\right)-\left(1-p\left(w_{r} / w_{u}, \lambda, i\right)\right)\right\}
$$

First-order conditions of maximisation yield $i^{*}=-e_{i} / 1+e_{i}$, where $e_{i}<0$ is the partial elasticity of the $p$-function with respect to the rate of interest. A meaningful solution of $i$ is an $i^{*}>0$ and that requires $\left|e_{i}\right|<1$. Since $e_{i}$ is a function of $w_{r} / w_{u}$, $\lambda$, and $i$, quite generally we can write

$$
i=\phi\left(w_{r} / w_{u}, \lambda\right)
$$$$
\cdots
$$

Normally we would expect the moneylender to charge a lower rate of interest when probability to quit increases to compensate for the loss in net returns and charge a higher rate of interest when that probability falls. Thus we assume $\phi_{1}>0$ and $\phi_{2}$ $>0$, that is we impose the following restrictions on the $\mathrm{p}$-function (at equilibrium): ${ }^{2}$

$$
\mathrm{p}_{31}>0 \text { and } \mathrm{p}_{32}>0
$$

${ }^{1}$ In this paper "to default" and "to quit to migrate" are equivalent concepts.

${ }^{2}$ Together with these we have the second-order condition which requires that $\mathrm{p}_{33}(1+\mathrm{i})$
Since ours is an equilibrium analysis, we rewrite the first-order condition, making use of the equilibrium condition [equations (2.5) and (2.6)] which yields

$$
\mathrm{i}=\psi(\lambda)
$$$$
\cdots
$$

Under the hypothesis introduced in equation (2.9) and the second-order condition of maximisation, $\psi^{\prime}(\lambda)$ cannot be signed. The implications of this will become clear when we see the solution graphically in the next section.

Now we consider the alternative objective function of the moneylender. Since the urban wage rate is given, the level of employment in the urban sector, $\mathrm{L}_{\mathrm{u}}$, is immediately obtained by the marginal productivity condition. The remaining labour force, $\mathscr{L}-\mathrm{L}_{\mathrm{u}}$, will either be employed in the rural sector or choose to remain unemployed in the urban sector. In the presence of consumption loans, the supply of labour to the rural sector, $\mathrm{L}_{\mathrm{r}}^{\mathrm{s}}$, is a function of the rural wage rate relative to the urban wage rate, the rate of urban unemployment and the rate of interest on consumption loans, i.e.

$$
\mathrm{L}_{\mathrm{r}}^{\mathrm{s}}=\mathrm{L}_{\mathrm{r}}^{\mathrm{s}}\left[\mathrm{w}_{\mathrm{r}} / \mathrm{w}_{\mathrm{u}}, \lambda, \mathrm{i}\right]
$$

where the partial derivatives of the $\mathrm{L}_{\mathrm{r}}^{\mathrm{s}}$ function with respect to its first two arguments are positive and that with respect to the third argument is negative. The moneylender can then affect the number of workers in the rural sector through variation in the rate of interest which maximises the interest income from a unit of money loaned out per person to the whole rural labour force, i.e.

$$
\operatorname{Max}_{i} \operatorname{iL}_{r}\left(w_{r} / w_{u}, \lambda, i\right)
$$

Since the partial derivatives of the $\mathrm{L}_{\mathrm{r}}$-function with respect to its arguments are the same as those of the $\mathrm{p}$-function, the first-order conditions of maximisation again yield a solution to the rate of interest in the form specified in equation (2.8) or (2.10).

\section{ANALYSIS OF THE MODEL}

Collecting equations from the previous section and making appropriate substitutions, we get our model as follows:

$$
\begin{aligned}
& \mathrm{L}_{\mathrm{r}}+(1+\lambda) \mathrm{L}_{\mathrm{u}}=\mathscr{L} \ldots \\
& \mathrm{P}_{\mathrm{r}} \mathrm{F}_{\mathrm{r}}^{\mathrm{L}}(1+\lambda)=\overline{\mathrm{w}}_{\mathrm{u}}(1+\mathrm{i})
\end{aligned}
$$




$$
\begin{aligned}
& \mathrm{i}=\psi(\lambda) \\
& \overline{\mathrm{w}}_{\mathrm{u}}=\mathrm{P}_{\mathrm{u}} \mathrm{F}_{\mathrm{u}}^{\mathrm{L}}
\end{aligned}
$$

So we have four equations in four variables, $L_{r}, L_{u}, \lambda$, and i. Given $w_{u}$ at $\bar{w}_{u}$, equation (3.4) solves for $L_{u}$ and thus effectively we have three equations, (3.1) to (3.3) to solve for $\mathrm{L}_{\mathrm{r}}, \lambda$ and $\mathrm{i}$, the parameters of our system being $\mathrm{K}_{\mathrm{r}}, \mathrm{K}_{\mathrm{u}}, \overline{\mathrm{w}}_{\mathrm{u}}, \mathscr{L}, \mathrm{P}_{\mathrm{r}}$ and $P_{u}$. The nature of the solution is depicted in Figures 1a to $1 \mathrm{c}$

The basic diagram is that used by Corden and Findlay [4], but with an additional curve $\mathrm{TT}^{\prime}$. It is the presence of $\mathrm{TT}^{\prime}$ that makes our analysis distinct and an explanation as to its origin is necessary. Recall that equation (2.6) gave us a relationship between $c_{r}, w_{r}$ and i. After making appropriate substitutions, the equation can be rewritten as

$$
\mathrm{c}_{\mathrm{r}}=\frac{\mathrm{P}_{\mathrm{r}} \mathrm{F}_{\mathrm{r}}^{\mathrm{L}}}{1+\psi\left[\frac{\mathscr{L}^{-\mathrm{L}_{\mathrm{r}}}}{\overline{\mathrm{L}}_{\mathrm{u}}}-1\right]}
$$

Since the urban wage rate is given at $\overline{\mathrm{w}}_{\mathrm{u}}, \overline{\mathrm{L}}_{\mathrm{u}}$ is fixed, and also given that the total labour force, $\mathscr{L}$, is fixed, equation (3.5) gives us a relationship in $\mathrm{c}_{\mathrm{r}}$ and $\mathrm{L}_{\mathrm{r}}$. Differentiating $\mathrm{c}_{\mathrm{r}}$ with respect to $\mathrm{L}_{\mathrm{r}}$, we get

$$
\frac{\mathrm{dc}_{\mathrm{r}}}{\mathrm{dL}_{\mathrm{r}}}=\frac{\mathrm{w}_{\mathrm{r}}}{\mathscr{L}(1+\mathrm{i}) \ell_{\mathrm{r}} \ell_{\mathrm{u}}}\left\{\ell_{\mathrm{u}} \eta_{\mathrm{r}}+\ell_{\mathrm{r}} \in \lambda\right\}
$$

where

$$
\begin{aligned}
& \frac{1}{\eta_{\mathrm{r}}}=\mathrm{d} \log \mathrm{L}_{\mathrm{r}} / \mathrm{d} \log \mathrm{w}_{\mathrm{r}}<0 \\
& \epsilon_{\lambda}=\psi^{\prime}(1+\lambda) / 1+\mathrm{i} \\
& \ell_{\mathrm{r}}=\mathrm{L}_{\mathrm{r}} / \mathscr{L} \text { and } \ell_{\mathrm{u}}=\mathrm{L}_{\mathrm{u}}(1+\lambda) / \mathscr{L}
\end{aligned}
$$

The sign of $\frac{\mathrm{dc}_{\mathrm{r}}}{\mathrm{dL}_{\mathrm{r}}}$, being dependent on the sign of $\epsilon_{\lambda}$, can be either positive or negative, and that is why three different $\mathrm{TT}^{\prime}$ curves have been drawn in Figures 1a to 1 c, where $\mathrm{TT}^{\prime}$ shows the relationship between $\mathrm{c}_{\mathrm{r}}$ and $\mathrm{L}_{\mathrm{r}}$. Note that the position of $\mathrm{TT}^{\prime}$ curve depends on $\mathscr{L}$ and $\overline{\mathrm{L}}_{\mathrm{u}}{ }^{3}$

$$
\begin{aligned}
& { }^{3} \text { To be specific } \\
& \frac{\mathrm{dc}_{\mathrm{r}}}{\mathrm{d} \mathscr{L}}=\frac{\mathrm{w}_{\mathrm{r}} \psi^{\prime}}{(1+\mathrm{i})^{2} \overline{\mathrm{L}}_{\mathrm{u}}} \text { and } \frac{\mathrm{dc}_{\mathrm{r}}}{\mathrm{d}_{\mathrm{u}}}=\frac{\mathrm{w}_{\mathrm{r}} \psi^{\prime}\left(\mathscr{L}-\mathrm{L}_{\mathrm{r}}\right)}{(1+\mathrm{i})^{2} \overline{\mathrm{L}}_{\mathrm{u}}^{2}} \text {. It also shows that the extent of }
\end{aligned}
$$

shift in $\mathrm{TT}^{\prime}$ due to changes in parameter values depends on $\psi^{\prime}$
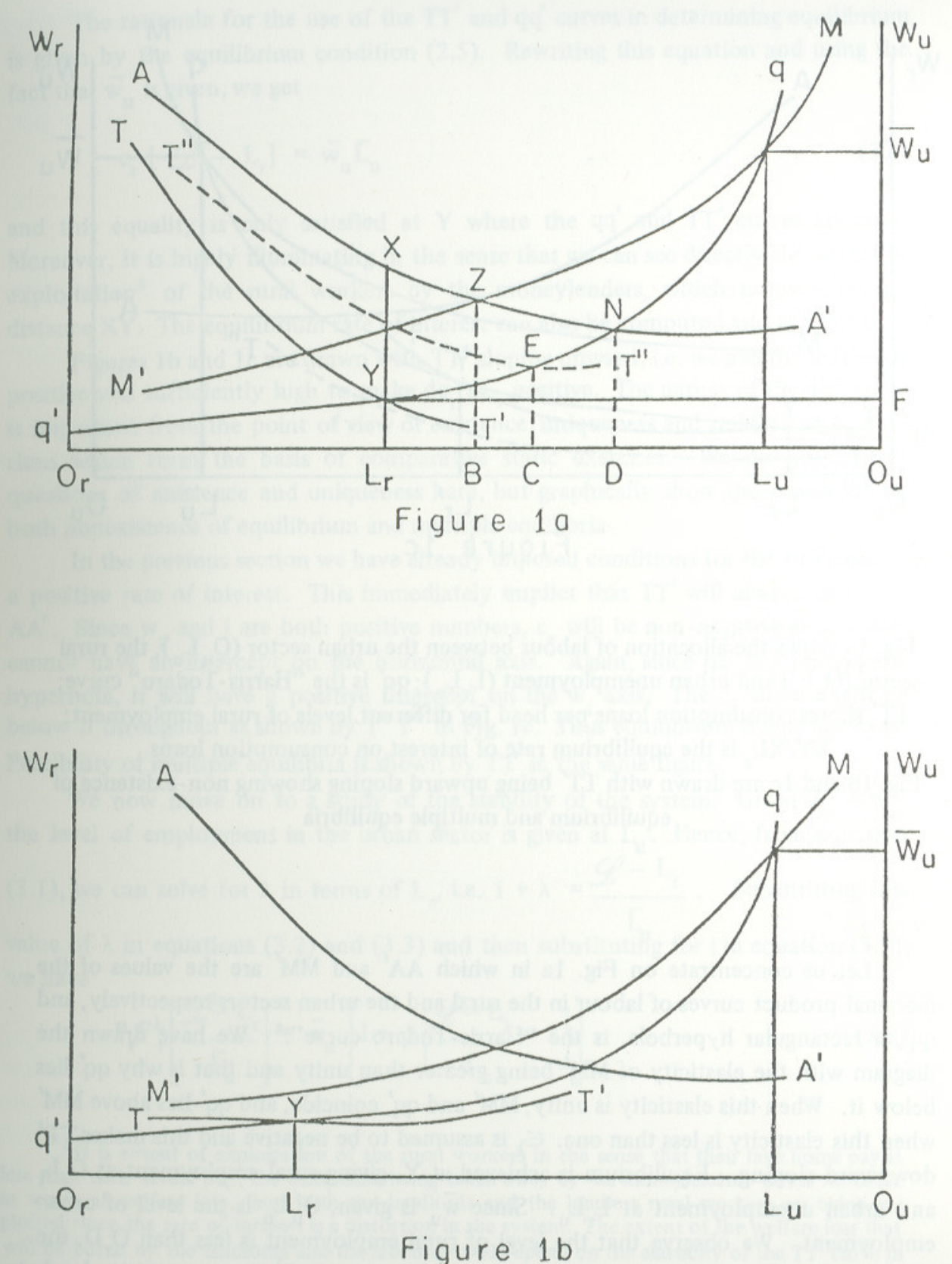

Figure 1b 
which is an equation in the variable $\mathrm{L}_{\mathrm{r}}$ only; for stability we specify the following dynamic process

$$
\begin{aligned}
& \dot{\mathrm{L}}_{\mathrm{r}}=\mathrm{F}\left[\mathrm{P}_{\mathrm{r}} \mathrm{F}_{\mathrm{r}}^{\mathrm{L}}\left\{\frac{\mathscr{L}-\mathrm{L}_{\mathrm{r}}}{\overline{\mathrm{L}}_{\mathrm{u}}}\right\}-\overline{\mathrm{w}}_{\mathrm{u}}\left\{1+\phi \frac{\mathrm{P}_{\mathrm{r}} \mathrm{F}_{\mathrm{r}}^{\mathrm{L}}}{\overline{\mathrm{w}}_{\mathrm{u}}}, \frac{\mathscr{L}-\mathrm{L}_{\mathrm{r}}}{\overline{\mathrm{L}}_{\mathrm{u}}}-1\right\}\right] \mathrm{F}^{\prime}>0 \\
& \mathrm{~F}(0)=0 \\
& \ldots
\end{aligned}
$$$$
\text { . }
$$

Equation (3.9) states that if the effective wage in the rural sector is greater than the expected wage in the urban sector, then the level of employment in the rural sector increases, $\mathrm{F}(\cdot)$ giving the rate of increase. $\overline{\mathrm{L}}_{\mathrm{r}}$, yields

Linearising the differential equation around the equilibrium value of $L_{r}$, say

$$
\dot{\mathrm{L}}_{\mathrm{r}}=\left(\mathrm{L}_{\mathrm{r}}-\overline{\mathrm{L}}_{\mathrm{r}}\right) \mathrm{F}^{\prime} \cdot \frac{\mathrm{w}_{\mathrm{r}}(1+\lambda)}{\mathscr{L}_{\mathrm{r}} \ell_{\mathrm{u}}}\left[\ell_{\mathrm{u}} \eta_{\mathrm{r}}-\ell_{\mathrm{r}}\left(1-\epsilon_{\lambda}^{\prime}\right)\right]
$$

The system is stable if and only if

$$
\ell_{\mathrm{r}}\left(1-\epsilon_{\lambda}\right)-\ell_{\mathrm{u}} \eta_{\mathrm{r}}>0
$$

and a sufficient condition for the system to be stable is $0 \leqq \epsilon_{\lambda} \leqq 1$. Since $\epsilon_{\lambda}$ can have any sign and magnitude, $\mathrm{TT}^{\prime}$ can be of the different shapes as seen in Figs. 1a to $\mathrm{c}$ and all of those equilibria cannot be stable. Moreover, since there is a possibility of multiple equilibria, as in Fig. 1c, all of those cannot be stable, too. What the stability condition is doing is that it is imposing a restriction on the slope of the $\mathrm{TT}^{\prime}$ around its points of intersection with $\mathrm{qq}^{\prime}$, i.e. the equilibrium point. Observe that the system is stable if $\epsilon_{\lambda}$ is negative. This implies from equation (3.6) that TT' is downward-sloping. Thus the equilibrium Y in Fig. 1a is stable. The question of instability arises when the $\mathrm{TT}^{\prime}$ curve is upward-sloping and we show graphically that under the adjustment process specified in equation (3.9) an equilibrium generated by an upward -sloping $\mathrm{TT}^{\prime}$ curve intersecting the $\mathrm{qq}^{\prime}$ curve from above is stable.

Consider the equilibrium $\mathrm{Y}$ in Figure 2. In that situation, $c_{r}\left(\mathscr{L}-\mathrm{L}_{\mathrm{r}}\right)=\bar{w}_{\mathrm{u}} \mathrm{L}_{\mathrm{u}}$ $=$ area $\mathrm{L}_{\mathrm{r}} \mathrm{YHO}_{\mathrm{u}}=$ area $\overline{\mathrm{w}}_{\mathrm{u}} \mathrm{SL}_{\mathrm{u}} \mathrm{O}_{\mathrm{u}}$. At this urban wage $\overline{\mathrm{w}}_{\mathrm{u}}$, at any level of employ. ment $\mathrm{O}_{\mathrm{r}} \mathrm{L}_{\mathrm{r}}^{\prime}$ greater than $\mathrm{O}_{\mathrm{r}} \mathrm{L}_{\mathrm{r}}, \mathrm{c}_{\mathrm{r}}\left(\mathscr{L}-\mathrm{L}_{\mathrm{r}}^{\prime}\right)=$ area $\operatorname{EIO}_{\mathrm{u}} \mathrm{L}_{\mathrm{r}}^{\prime}<$ area $\mathrm{FGO}_{\mathrm{u}} \mathrm{L}_{\mathrm{r}}^{\prime}=$ area $\bar{w}_{u} \mathrm{SL}_{u} \mathrm{O}_{u}$ : Under the given adjustment process, this implies that $\dot{\mathrm{L}}_{\mathrm{r}}$ is negative Similarly, $\mathrm{L}_{\mathrm{r}}$ will be positive for any level of rural employment less than $\mathrm{O}_{\mathrm{r}} \mathrm{L}_{\mathrm{r}}$ at the given urban wage rate $\bar{w}_{u}$. So, the equilibrium is stable. Under the same adjustment process, the equilibrium $Y^{\prime}$ in Fig. $1 \mathrm{~b}$ is unstable. The necessary and sufficient condition for stability is the algebraic expression of the nature of the intersection between $\mathrm{qq}^{\prime}$ and $\mathrm{TT}^{\prime}$.

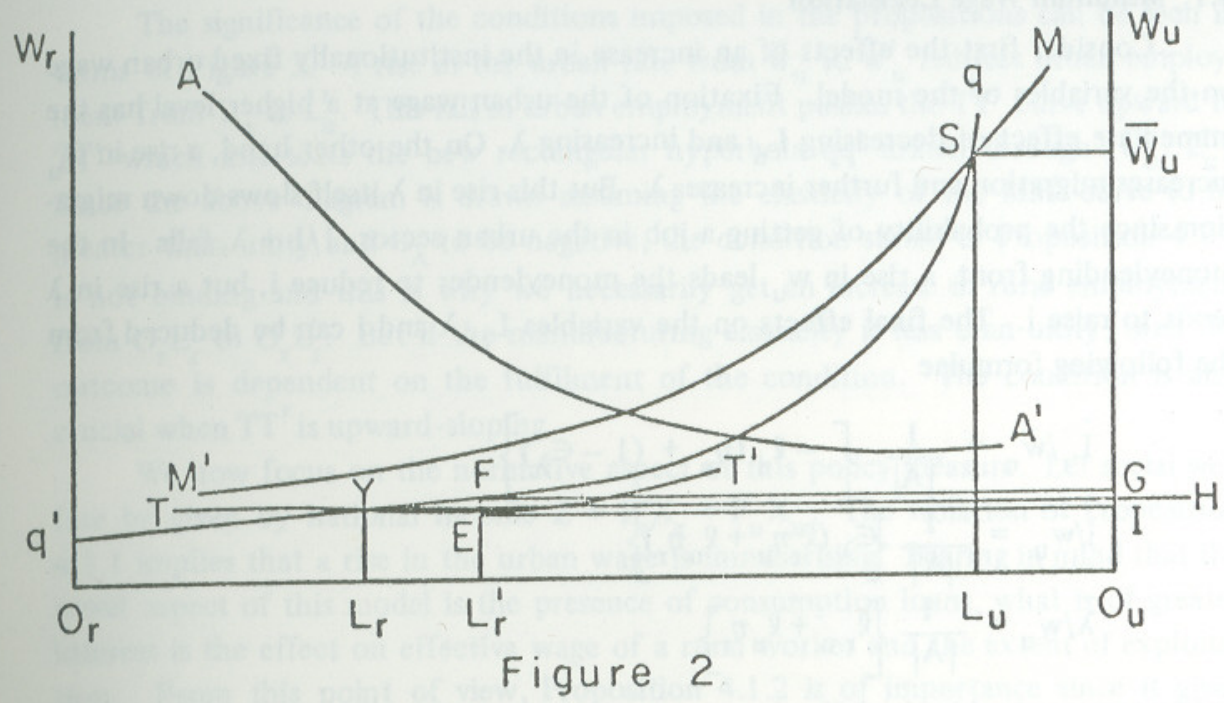

Stability analysis in the H-T framework with consumption loans in the rural sector

\section{DEVELOPMENT POLICIES}

In this section we perform some comparative static exercises which bring out the significance of this work and help in evaluating different policies in this setting.

The equations relevant for comparative static exercises are (3.1) to (3.4), whose total differentiation yields

$$
\left[\begin{array}{cccc}
\ell_{\mathrm{r}} & \ell_{\mathrm{u}} & \ell_{\mathrm{u}} & 0 \\
\eta_{\mathrm{r}} & 1 & 0 & -1 \\
0 & \epsilon_{\lambda} & 0 & -1 \\
0 & 0 & \eta_{\mathrm{u}} & 0
\end{array}\right]
$$$$
\left[\begin{array}{c}
\hat{\mathrm{L}}_{\mathrm{r}} \\
\hat{\lambda} \\
\hat{\mathrm{L}}_{\mathrm{u}} \\
\hat{\mathrm{i}}
\end{array}\right]=\left[\begin{array}{c}
\hat{\mathscr{L}} \\
\hat{\mathrm{w}}_{\mathrm{u}}-\hat{\mathrm{p}}_{\mathrm{r}}-\hat{\mathrm{K}}_{\mathrm{r}} / \rho_{\mathrm{r}} \\
0 \\
\hat{\mathrm{w}}_{\mathrm{u}}-\hat{\mathrm{p}}_{\mathrm{u}}-\hat{\mathrm{K}}_{\mathrm{u}} / \rho_{\mathrm{u}}
\end{array}\right]
$$

i.e. $\mathrm{Ax}=\mathrm{b}$ where $\frac{1}{\eta_{\mathrm{u}}}=\frac{\partial \log \mathrm{L}_{\mathrm{u}}}{\partial \log \mathrm{w}_{\mathrm{u}}}, \rho_{\mathrm{j}}=\frac{\partial \log \mathrm{K}_{\mathrm{j}}}{\partial \log \mathrm{w}_{\mathrm{j}}}, \mathrm{j}=\mathrm{r}, \mathrm{u}$ and any variable $\hat{\mathrm{z}}=\frac{\mathrm{dz}}{\mathrm{z}}$ represents a proportional change in that variable. It can easily be checked that the stability condition implies $|\mathrm{A}|<0$ 


\subsection{Minimum Wage Legislation}

Consider first the effects of an increase in the institutionally fixed urban wage on the variables of the model. Fixation of the urban wage at a higher level has the immediate effect of decreasing $L_{u}$ and increasing $\lambda$. On the other hand, a rise in $w_{u}$ increases migration and further increases $\lambda$. But this rise in $\lambda$ itself slows down migration since the probability of getting a job in the urban sector, $1 / 1+\lambda$, falls. In the moneylending front, a rise in $w_{u}$ leads the moneylender to reduce $i$, but a rise in $\lambda$ tends to raise $i$. The final effects on the variables $L_{r}, \lambda$ and $i$ can be deduced from the following formulae

$$
\begin{aligned}
& \hat{\mathrm{L}}_{\mathrm{r}} / \hat{\mathrm{w}}_{\mathrm{u}}=\frac{1}{|\mathrm{~A}|}\left\{-\ell_{\mathrm{u}}\left(\eta_{\mathrm{u}}+\left(1-\epsilon_{\lambda}\right)\right\}\right. \\
& \hat{\mathrm{i}} / \mathrm{w}_{\mathrm{u}}=\frac{1}{|\mathrm{~A}|}\left\{\epsilon_{\lambda}\left(\ell_{\mathrm{r}} \eta_{\mathrm{u}}+\ell_{\mathrm{u}} \eta_{\mathrm{r}}\right)\right\} \\
& \hat{\lambda} / \hat{w}_{u}=\frac{1}{|\mathrm{~A}|}\left[\ell_{\mathrm{r} u}+\ell_{\mathrm{u}} \eta_{\mathrm{r}}\right\}
\end{aligned}
$$

and are summarised in the following propositions:

\section{Proposition 4.1.1}

An increase in the urban wage rate unambiguously decreases urban employment and increases the unemployment rate. It will increase rural employment if and only if $\left|\eta_{\mathrm{u}}\right|<\left(1-\epsilon_{\lambda}\right)$ and either $\epsilon_{\lambda}<0$ or $0 \leqq \epsilon_{\lambda}<1$. It will also decrease rural employment if $\in_{\lambda} \geqq 1$.

\section{Proposition 4.1.2}

With an increase in the urban wage rate, the rate of interest on consumption loans increases, remains constant or decreases if and only if $\in_{\lambda}$ is greater than, equal to, or less than zero respectively.

\section{Remark 4.1}

Even if $\left|\eta_{u}\right|=1$, the rural unemployment level will change so long as $\in_{\lambda} \neq 0$.

Observe that $\in_{\lambda}$ plays a crucial role in the propositions. An immediate implication of this is that the restrictions on the parameter values in Corden and Findlay [4] need to be modified and that and this is stated in Proposition 4.1.1 and is seen even more clearly from Remark 4.1. In diagrammatic terms, when the manufacturing elasticity is equal to unity, then the rectangular hyperbola qq' coincides with $\mathbf{M M}^{\prime}$ and thus in their model an increase in minimum wage has no effect on rural employment. But in our model, the moment the urban employment level changes, the TT' curve shifts, giving a new level of rural employment. What is even more important is that they do not have anything like Proposition 4.1.2 whereby implications of policy issues on distribution of income can be singled out.
The significance of the conditions imposed in the propositions can be seen in terms of Figure 3. A rise in the urban rate from $\vec{w}_{u}$ to $\bar{w}_{u}^{\prime}$ reduces urban employment from $\mathrm{L}_{\mathrm{u}}$ to $\mathrm{L}_{\mathrm{u}}^{\prime}$. This fall in urban employment pushes the TT' curve upward to $\overline{\mathrm{TT}}^{\prime}$ which intersects the new rectangular hyperbola $\mathrm{qq}^{\prime}$ drawn through $\left(\overline{\mathrm{w}}_{\mathrm{u}}^{\prime}, \mathrm{L}_{\mathrm{u}}^{\prime}\right)$. Since the above diagram is drawn assuming the elasticity of the $\mathrm{MM}^{\prime}$ curve to be greater than unity and $\epsilon_{\lambda}$ to be negative, the condition stated in Proposition 4.1.1 is not binding and this is why we necessarily get an increase in rural employment from $\mathrm{O}_{\mathrm{r}} \mathrm{L}_{\mathrm{r}}$ to $\mathrm{O}_{\mathrm{r}}^{\prime} \mathrm{L}_{\mathrm{r}}^{\prime}$. But if the manufacturing elasticity is less than unity, then the outcome is dependent on the fulfilment of the condition. The condition is also crucial when $\mathrm{TT}^{\prime}$ is upward-sloping.

We now focus on the normative aspect of this policy measure. Let social welfare be given by national income $Z=P_{r} X_{r}+P_{u} X_{u}$. The violation of Proposition 4.1.1 implies that a rise in the urban wage is immiserising. Bearing in mind that the novel aspect of this model is the presence of consumption loans, what is of greater interest is the effect on effective wage of a rural worker and the extent of exploitation. From this point of view, Proposition 4.1.2 is of importance since it gives conditions under which the rate of interest will increase. If this is accompanied with a fall in the rural wage rate, then the effective wage of a rural worker (and hence his welfare) falls.

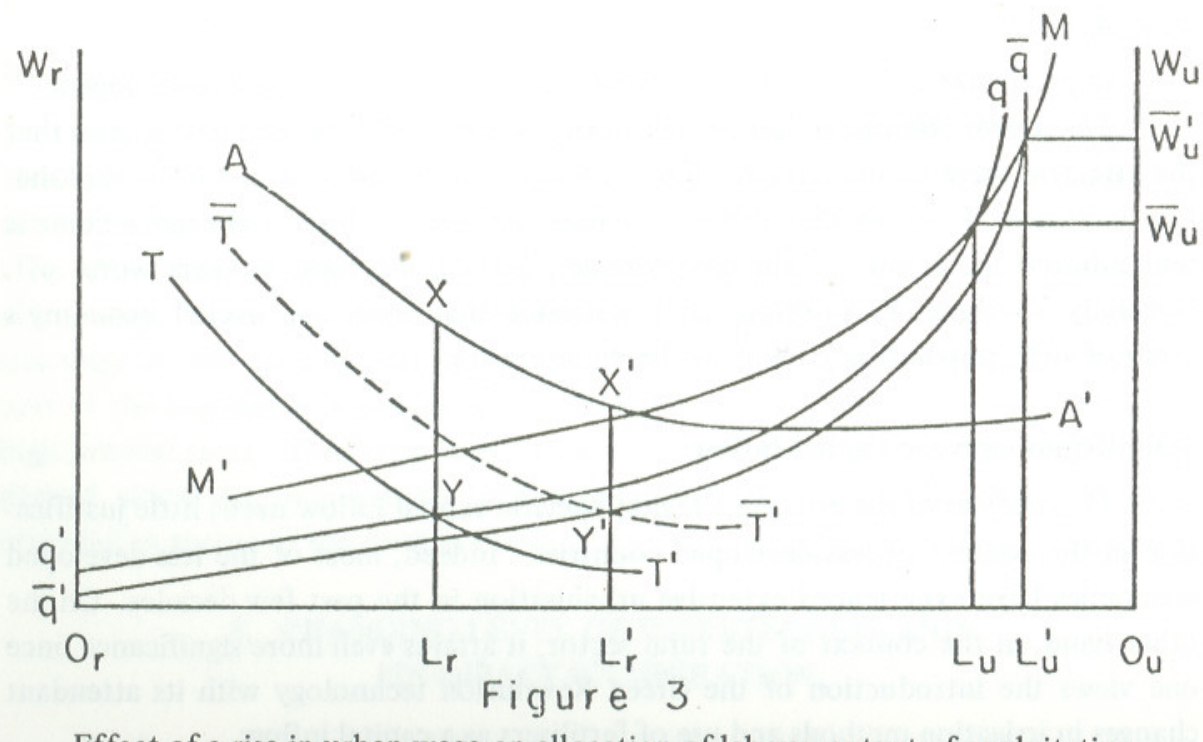

Effect of a rise in urban wage on allocation of labour, extent of exploitation and rate of interest on consumption loans 


\subsection{Population Growth}

Rural sectors of less developed countries generally experience huge population pressure because of high rate of growth of population as such and near-stagnant urban centres. Given a fixed urban wage, the increase in labour force either gets employed in the rural sector or joins the unemployment pool. The growth in unemployment discourages the rural people from migrating and they tend to stay in the rural sector since the probability of getting a job in the urban sector falls. This enhances the "pool" of the exploited in the rural sector. The positive effects of population growth is stated in the following proposition and the normative effects can be derived from it.

\section{Proposition 4.2.1}

Population growth unambiguously increases the urban unemployment rate. It will increase rural employment if and only if $\epsilon_{\lambda}<1$. The urban employment level remains unchanged.

\section{Proposition 4.2.2}

With an increase in population, the rate of interest on consumption loans increases, decreases, or remains constant, if and only if $\in_{\lambda}$ is positive, zero or negative.

\section{Remark 4.2.1}

In particular, if $\in_{\lambda}=1$, then the rural employment level remains unchanged.

The above remark, combined with Proposition 4.2.2, immediately implies that the effective wage of the already employed deteriorates, and the extent of exploitation increases. It shows that although overall the welfare doesn't change, income is redistributed in favour of the moneylender, leaving the rural workers worse off. Generally speaking, Proposition 4.2.1 indicates that from the overall economy's point of view, population growth can be immiserising.

\subsection{Region-specific Capital Inflow}

The analysis of the effects of region-specific capital inflow needs little justification in the context $\mathrm{cf}$ less developed countries. Indeed, most of the less developed economies have experienced extensive urbanisation in the past few decades. On the other hand, in the context of the rural sector, it attains even more significance once one views the introduction of the Green Revolution technology with its attendant changes in irrigation methods and use of fertilisers as a capital inflow.

Inspection of the equation system (4.1) yields the following proposition.

\section{Proposition 4.3}

Increase in capital inflow in the urban sector increases urban employment and reduces the unemployment rate. It will increase rural employment if and only if $\epsilon_{\lambda}<1$. Increase in capital inflow in the rural sector increases rural employment and decreases the unemployment rate. In both cases, the rate of interest on consumption loans will increase, remain constant, decrease, if and only if $\in_{\lambda}$ is negative, zero or positive.

The reader can carry on his own welfare analysis along the lines suggested in the previous subsections.

\subsection{Wage Subsidies in Agriculture}

Farmers in less developed countries are subsidised in different ways. They are supplied with fertilisers, water for irrigation and other agricultural inputs at subsidised rates. Again, they are given price support for the final good. Here we note the effects of subsidising wage costs of the agricultural producers.

The algebraic structure needed in deriving the following proposition can be arrived at by replacing equation (3.2) by

$$
\left(\mathrm{P}_{\mathrm{r}} \mathrm{F}_{\mathrm{r}}^{\mathrm{L}}+\mathrm{s}_{\mathrm{r}}\right)(1+\lambda)=\overline{\mathrm{w}}_{\mathrm{u}}(1+\mathrm{i})
$$$$
\cdots
$$

respectively and then totally differentiating the system of equations (3.1), $\left(3.2^{\prime}\right)$ and (3.3), where $s_{r}$ stands for wage subsidy.

\section{Proposition 4.4}

An increase in wage subsidy, $s_{r}$, has positive and normative effects similar to those of capital accumulation in the rural sector. The effect on the rate of interest is given by the condition stated in Proposition 4.3.

It is of interest to note that although an increase in wage subsidies increases the actual wage of the agricultural labourers it will not lead to an increase in their effective wage by the same amount if $\epsilon_{\lambda}$ is negative. In fact, it might even fall. That is, part of the increase in subsidies will be absorbed by the village moneylender through high interest rates. Thus wage subsidies will not have the effects to the extent that is desired since the moneylender will syphon off part of the benefits that were intended to accrue to the rural workers.

\section{CHANGING LEVEL OF INDEBTEDNESS AND ITS IMPACT ON MIGRATION}

So far we have assumed that the level of outstanding debt of the peasants is always zero, i.e. we were observing a steady state. In this section we analyse the implications of the changing level of indebtedness of the peasantry. The existence of 
outstanding debt implies that the rural workers borrow more than their post-harvest income, $w_{r}$. Moneylenders allow this to happen presumably because they can absorb whatever assets the peasant has. Examples of such assets are jewellery, utensils and residential structures, and it is the non-acceptance of these assets as valid collaterals by the organised credit market that forces the peasants to go to the moneylender.

In order to determine the volume of consumption loans per worker in the rural sector, we consider a simple borrowing and lending process where, in the beginning of a period, a rural worker gets a loan equal to the discounted value of his assets and repays it with interest from the wages earned at the end of the period. Let $\bar{A}$ be the value of assets a worker is endowed with in the beginning of period $t$ and let $\mathrm{i}^{\mathrm{t}}$ be the rate of interest fixed by the moneylender in that period. Then the volume of consumption loan, $c_{r}^{t}$, he can get is $\bar{A} / 1+i^{t}$. At the end of the period he earns wages $\mathrm{w}_{\mathrm{r}}^{\mathrm{t}}$ and repays the loan compounded by the current rate of interest. If $\mathrm{w}_{r}^{\mathrm{t}}>\mathrm{c}_{\mathrm{r}}^{\mathrm{t}}$ $\left(1+\mathrm{i}^{\mathrm{t}}\right)=\overline{\mathrm{A}}$, then the rural worker can free all his assets from the moneylender and thus consumption in period $(t+1)$ will be given by $c_{r}^{t+1}=\frac{\bar{A}}{1+i^{t+1}}+\left(w_{r}^{t}-\bar{A}\right)$. If $\mathrm{w}_{\mathrm{r}}^{\mathrm{t}}<\overline{\mathrm{A}}$, then the rural worker loses assets equal to the value of the outstanding debt and his commitments at the end of the next period include interest payment on the outstanding debt. Let $D^{t+1}=\bar{A}-w_{r}^{t}$ where $D^{t+1}>0$ indicates that the rural worker is in debt in the beginning of period $t+1$, and $D^{t+1}<0$ indicates that the worker carries over a surplus from the previous period. So the above equation can be rewritten as

$$
c_{r}^{t+1}\left(1+i^{t+1}\right)+D^{t+1}\left(1+i^{t+1}\right)=\bar{A}
$$

The movement of debt per person, D, over time plays an important role in this paper and let us specify the equation that describes its movement. In terms of discrete time periods,

$$
\begin{aligned}
& D^{t+2}=c_{r}^{t+1}\left(1+i^{t+1}\right)+D^{t+1}\left(1+i^{t+1}\right)-w_{r}^{t+1} \\
& D^{t+2}=\bar{A}-W_{r}^{t+1}
\end{aligned}
$$

Equation (5.2) is a first order non-linear difference equation in D since $w_{r}^{t+1}$ is a function of $\mathrm{D}^{\mathrm{t}+1}$.

In the $\mathrm{p}$-function we introduce $\mathrm{D}$ as an argument showing that the decision to quit or stay depends on the level of indebtedness also. So

$$
\mathrm{p}=\mathrm{p}\left(\mathrm{w}_{\mathrm{r}} / \mathrm{w}_{\mathrm{u}}, \lambda, \mathrm{i}, \mathrm{D}\right)
$$

where we assume, as before, that $\mathrm{p}_{1}>0, \mathrm{p}_{2}>0, \mathrm{p}_{3}<0$ and $\mathrm{p}_{4}<0$. The maximisation problem of the moneylender is then given by

$$
\underset{i}{\operatorname{Max}}\left\{\left(c_{r}+D\right) \operatorname{ip}\left(w_{r} / w_{u}, \lambda, i, D\right)-\left(1-p\left(w_{r} / w_{u}, \lambda, i, D\right)\right) c_{r}\right\}
$$

where we assume that the moneylender can recoup the capital value of the outstanding debt. The first-order conditions of maximisation yield $i^{*}=\frac{1}{-e_{p} \cdot p[1-D / \bar{A}]}-1$, where $e_{p}$ is the partial elasticity of the $p$-function with respect to the rate of interest. A meaningful solution of $i$ is an $i^{*}>0$ and a sufficient condition for that is $\left|e_{p}\right|<1$. Since $e_{p}$ is a function of $w_{r} / w_{u}, \lambda, i$ and $D$, quite generally we can write

$$
\mathrm{i}=\phi\left(\mathrm{w}_{\mathrm{r}} / \mathrm{w}_{\mathrm{u}}, \lambda, \mathrm{D}\right) \quad \ldots \quad \ldots
$$

where we assume that $\phi_{1}>0, \phi_{2}>0$ and $\phi_{3}<0$, that is, we impose the following restrictions on the $\mathrm{p}$-function (at equilibrium) $:^{6}$

$$
\mathrm{p}_{31}>0, \mathrm{p}_{32}>0 \text { and } \mathrm{p}_{34}(1-\mathrm{D} / \overline{\mathrm{A}})-\mathrm{p}_{3} / \overline{\mathrm{A}}<0
$$

Collecting equations and making appropriate substitutions, we have our model now as follows :

$$
\begin{array}{lll}
\mathrm{L}_{\mathrm{r}}+(1+\lambda) \overline{\mathrm{L}}_{\mathrm{u}}=\mathscr{L} & \ldots & \ldots \\
(\overline{\mathrm{A}} / 1+\mathrm{i}-\mathrm{D})(1+\lambda)=\overline{\mathrm{w}}_{\mathrm{u}} & \ldots & \ldots \\
\mathrm{i}=\phi\left(\mathrm{P}_{\mathrm{r}} \mathrm{F}_{\mathrm{r}}^{\mathrm{L}} / \overline{\mathrm{w}}_{\mathrm{u}}, \lambda, \mathrm{D}\right) & \ldots & \ldots \\
\mathrm{D}^{\mathrm{t}+1}=\overline{\mathrm{A}}-\mathrm{P}_{\mathrm{r}} \mathrm{F}_{\mathrm{r}}^{\mathrm{L}}(\mathrm{t}) & \ldots & \ldots
\end{array}
$$

Given any value of $D$, equations (5.5) to (5.7) solve for $L_{r}, \lambda$ and $i$, where $L_{u}$ is determined by the assumption that the urban wage rate is fixed at $\bar{w}_{u}$ and the marginal productivity condition. This we denote as the temporary equilibrium of our model, the parameters being $\overline{\mathrm{A}}, \mathrm{K}_{\mathrm{r}}, \mathrm{K}_{\mathrm{u}}, \mathscr{L} \overline{\mathrm{w}}_{\mathrm{u}}, \mathrm{P}_{\mathrm{r}}$ and $\mathrm{P}_{\mathrm{u}}$. Once this equilibrium is reached, it determines the change in $\mathrm{D}$, and another temporary equilibrium is arrived at in the

${ }^{6}$ Together with these we have the second-order condition which requires that $(1-\mathrm{D} / \overline{\mathrm{A}})$ $\left\{p_{33}(1+i)+p_{3}\right\}-\frac{1}{(1+i)^{2}}<0$. 
next period. If the difference equation has a unique and stable rest point, ${ }^{7}$ then the successive temporary equilibria will eventually converge to a steady state, i.e. $D^{t+j}=D^{t+j-1}$ for all $j$. Solution to the difference equation requires $L_{r}$ to be a function of $\mathrm{D}$ since $\mathrm{P}_{\mathrm{r}} \mathrm{F}_{\mathrm{r}}^{\mathrm{L}}$ is a function of $\mathrm{L}_{\mathrm{r}}$. For this, we appeal to equations (5.5) to (5.7) whose total differentiation, keeping the other parameter values constant, yields

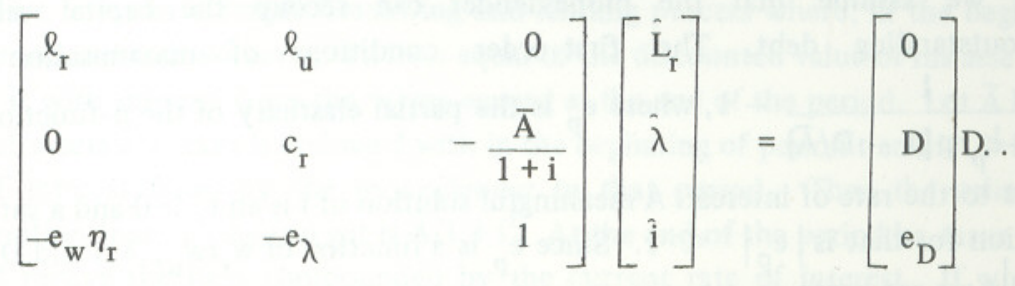

i.e. $\mathrm{Bx}=\mathrm{b}$

where $\hat{\mathrm{L}}_{\mathrm{r}}=\frac{\mathrm{dL}}{\mathrm{r}}, \hat{\mathrm{D}}=\frac{\mathrm{dD}}{\mathrm{D}}, \hat{\lambda} \frac{\mathrm{d} \lambda}{1+\lambda}, \hat{\mathrm{i}}=\frac{\mathrm{di}}{1+\mathrm{i}}$ and $\mathrm{e}_{\mathrm{D}}=\frac{\partial \mathrm{i}}{\partial \mathrm{D}} \cdot \frac{\mathrm{D}}{1+\mathrm{i}}<0$.

It can be easily checked that the stability condition of the temporary equilibrium implies that $|\mathrm{B}|>0$.

From equation (5.9) we get $\hat{\mathrm{L}}_{\mathrm{r}} / \hat{\mathrm{D}}=\frac{1}{|\mathrm{~B}|}\left[-\ell_{\mathrm{u}}\left\{\mathrm{D}\left(\mathrm{e}_{\mathrm{D}}+1\right)+\mathrm{c}_{\mathrm{r}} \mathrm{e}_{\mathrm{D}}\right\}\right]$ So, $\hat{\mathrm{L}}_{\mathrm{r}} / \mathrm{D}>0$ if $\left|\mathrm{e}_{\mathrm{D}}\right| \geqq 1$. That is with an increase in debt, if the rate of interest falls more than proportionately, then the level of rural employment will increase. But if $\left|e_{D}\right|<1$ and $D\left(e_{D}+1\right)>c_{r} e_{D}$, then an increase in the level of outstanding debt will lead to an increase in migration and lower rural employment.

Let us rewrite equation (5.2) as

$$
D^{t+2}=\bar{A}+f\left(D^{t+1}\right) . \text { Then } f^{\prime}\left(D^{t+1}\right)=-P_{r} F_{r}^{L L} \frac{d L_{r}}{d D}
$$

It is well known that if (a) $0<\mathrm{f}^{\prime}<1$ or (b) $-1<\mathrm{f}^{\prime}<0$ then the rest point of the difference equation is stable. On the other hand, if (c) $f^{\prime}>1$ or (d) $f^{\prime}<-1$, then it is unstable. Note that in cases (b) and (d) we get oscillations in the value of D over time.

The above discussion indicates that if the difference equation has a unique rest point, then there are different possible outcomes associated with changes in the level of rural indebtedness. The chart below, summarises the final effects of variation

${ }^{7}$ Observe that the steady-state value of D, i.e. D ${ }^{*}$, can be negative. Given the steady-state configuration of the other variables, in spite of the workers having to take loans in the beginning of a period, they might end up with a surplus at the end of each period. But the analysis in this paper has been done keeping in mind a positive value of $\mathrm{D}$, a state commonly observed in less developed countries. in the debt level on migration from the rural to the urban sector, and the arrows indicate the direction of change.

\begin{tabular}{|c|c|c|c|c|}
\hline & \multicolumn{2}{|c|}{$\mathrm{D}^{*}$ is stable } & \multicolumn{2}{|c|}{$\mathrm{D}^{*}$ is unstable } \\
\hline & $\mathrm{D}>\mathrm{D}^{*}$ & $\mathrm{D}<\mathrm{D}^{*}$ & $\mathrm{D}>\mathrm{D}^{*}$ & $\mathrm{D}<\mathrm{D}^{*}$ \\
\hline$\hat{\mathrm{L}}_{\mathrm{r}} / \hat{\mathrm{D}}<0$ & $\downarrow$ & $\uparrow$ & 3 & $?$ \\
\hline$\hat{\mathrm{L}}_{\mathrm{r}} / \hat{\mathrm{D}}>0$ & $\begin{array}{ll}\uparrow & \\
& 5\end{array}$ & $\downarrow$ & $\downarrow$ & $\uparrow$ \\
\hline
\end{tabular}

Note: Chart indicating effects on variation in the debt level on migration, the arrows indicating the direction of change in migration.

Box 1 in the chart indicates that outstanding debt will eventually approach its rest point and a decrease in migration will be observed. But the approach is an oscillatory one. Box 2 in the chart, on the other hand, gives us an interesting result. It shows that increased indebtedness is associated with increased migration, a phenomenon commonly observed in less developed countries. The peasants begin with a level of outstanding debt less than the steady-state level $\mathrm{D}^{*}$. As debt increases, people have the rural sector and join the urban unemployed. This has two effects. Under the assumption of a rigid urban wage rate, an increase in the number of the unemployed decreases the probability of getting a job in the urban sector and hence discourages migration. On the other hand, as people leave the rural sector, the rural wage rate increases making it easier for the peasants to pay off their debts. A fall in the rate of interest also helps in slowing down migration and the process stops when the correct configuration of $D, w_{r}, i, w_{u}$ and $\lambda$ is arrived at. At $D^{*}$, the level of indebtedness of the peasantry does not change. And given the urban wage rate and rate of urban unemployment, it is not worth-while to migrate also. The combinations given in Boxes 3 and 4 do not give us any definitive idea about what happens to migration. Since we have explosive oscillations, all we can say is that irrespective of where we start from, the level of $\mathrm{D}$ will gradually move away from $\mathrm{D}^{*}$. Boxes 5 to 8 give us situations where we have either monotonic convergence or divergence. 


\section{CONCLUSION}

In a very simple framework, this paper has brought out the importance of the study of institutional arrangements in the rural sectors of less developed countries and the bearing it has on evaluating the effects of different policies. Models without consumption loans give an imprecise idea about the effectiveness of policy instruments since they ignore the presence of rural moneylenders who syphon off part of the benefits that are supposed to accrue to the agricultural labourers. Indeed, we observe within our simple framework that measures aimed at improving the welfare of the agricultural labourers might actually improve that of the moneylenders, leaving the workers with an even lower effective wage, a dimension which has not been captured in the literature. An added dimension of the paper is that it provides a framework through which the effects of changing level of indebtedness on migration can be captured. To be specific, we showed that under certain conditions, increasing indebtedness will force people to leave the rural sector and join the urban unemployed. Development policy analysis can also be carried out in the presence of debt. In their concluding section of [6], Harris and Todaro discuss policies like migration restrictions as welfare-improving. But, within our model, in effect, it will lead to strengthening the position of the village moneylender who can now exploit the peasantry even more. So, before imposing such restrictions, what is initially required is freeing of these labourers from their indebtedness.

\section{REFERENCES}

1. Bhaduri, A. "A Study in Agricultural Backwardness under Semi-feudalism". Economic Journal. pp. 120-137.

2. Bhagwati, J., and T. N. Srinivasan. "The Ranking of Policy Interventions under Factor Market Imperfections: The Case of Sector-Specific Sticky Wages and Unemployment". Sankhya, Series B. 1973. pp. 405-420.

3. Calvo, G. A. "Urban Unemployment and Wage Determination in LDC's: Trade Unions in the Harris-Todaro Model". International Economic Review. 1978. pp. 65-81.

4. Corden, W. M., and R. Findlay. "Urban Unemployment, Intersectoral Capital Mobility and Development Policy”. Economica. Vol. XLII. 1975. pp. 59-78.

5. Gersovitz, M. "Aggregative Demand, the Wage Gap and Unemployment in LDC's". Journal of Development Economics. 1974. pp. 235-246.

6. Harris, J. R., and M. Todaro. "Migration, Unemployment and Development: A Two-Sector Analysis". American Economic Review. Vol. LX. 1970. pp. $126-142$.
7. Khan, M. Ali. "The Harris-Todaro Hypothesis and the Heckscher-OhlinSamuelson Trade Model: A Synthesis". Journal of International Economics. Vol. X. 1980. pp. 527-547.

8. Lipton, M. "Migration from Rural Areas of Poor Countries: The Impact on Rural Productivity and Income Distribution". In R. H. Sabot (ed.), Migration and the Labour Market in Developing Countries. (Proceedings of a conference held by the World Bank, May 1978) (Boulder, Colorado: The Westview Press). pp. 191-228.

9. Stiglitz, J. E. "Alternative Theories of Wage Determination and Unemployment in LDC's: The labour-Turnover Model". Quarterly Journal of Economics. Vol. LXXXVIII, 1974. pp. 194-227. 